\title{
Determinants of Organizational Design Choices in Spanish Nongovernmental Development Organizations
}

\author{
Victor Martín-Pérez, Natalia Martín-Cruz, Juan Hernangómez-Barahona \\ Business Department, University of Valladolid, Valladolid, Spain \\ Email address: \\ vmartin@eco.uva.es (V. Martín-Pérez), ambiela@eco.uva.es (N. Martín-Cruz), jhernan@eco.uva.es (J. Hernangómez-Barahona)
}

\section{To cite this article:}

Victor Martín-Pérez, Natalia Martín-Cruz, Juan Hernangómez-Barahona. Determinants of Organizational Design Choices in Spanish Nongovernmental Development Organizations. European Business \& Management. Vol. 3, No. 3, 2017, pp. 47-56.

doi: $10.11648 /$ j.ebm.20170303.12

Received: January 17, 2017; Accepted: June 22, 2017; Published: July 27, 2017

\begin{abstract}
This paper adds to the scant literature on the internal structure of organizations by focusing on the organizational design of nongovernmental development organizations (NGDOs). Specifically, we evaluate prominent Spanish NGDOs during 2010 to determine the balance of two key organizational design choices at the NGDO's project department: delegation of authority to lower-level employees and the provision of incentive compensation to ensure that these employees do not misuse their discretion. We develop a simultaneous model of these two choices that treats delegation and incentive compensation as endogenous variables. The results of our empirical analysis provide evidence that delegation of decision rights and incentive compensation systems are interdependent allowing scholars and practitioners a better understanding of the determinants of organizational design choices.
\end{abstract}

Keywords: Delegation, Incentive Compensation, Job Authority, NGDOs, Nonprofit Organizations

\section{Introduction}

The growing role of nongovernmental development organizations (NGDOs) in development activities throughout the world has involved an increase in the number of employees and the amount of financial resources they handle as well as the complexity of the performed tasks. Because managers of NGDOs cannot make every decision necessary for the organization to run effectively, they are faced with two critical organizational design decisions: How much authority should they delegate to their employees to make better use of their knowledge, and how should they design their incentive compensation package so that the employees undertake the desired actions yet avoid misusing their discretion [1], [2]? In other words, the assignment of decision rights must effectively link the authority for decision making and action with the necessary relevant information and motivation for good decision making. The incentive compensation should take into account the employees' responsibilities [3] and performance [4] to influence their effort and behaviour toward organizational objectives.

Theoretical research argues that delegation of authority and incentive compensation are complementary organizational design choices made by management (i.e., they are endogenous) [5], [6]. However, the empirical evidence is scarce and limited to manufacturing firms [7], [8], [9]. Our study contributes to the literature on the economics of organizational design by extending these prior empirical studies to a new field, namely, the nonprofit sector. We provide evidence that delegation of decision rights and incentive compensation are interdependent organizational design choices, addressing this research gap in the nonprofit sector. To the best of our knowledge, this paper is the first study to analyze the joint nature of the delegation of decision rights and incentive compensation of nonprofit organizations within the framework of agency theory.

Despite having idiosyncratic features, nonprofit organizations deal with the division of decision making and risk bearing, which allows us to estimate these internal choices according to agency theory. Specifically, we study NGDOs, which are homogeneous in terms of their activity and goals pursued; namely, they are nonprofits specialized in developing countries. Because NGDOs activities have a strong international component, a detailed knowledge of the countries involved is necessary. Consequently, varying levels of delegation of decision rights are required. Furthermore, although the nonprofit sector has become more professional 
in recent years, much of the activity is still in the hands of participants who are not primarily motivated by financial compensation -i.e., salary, allowance for travel expenses, bonus-, preferring rather nonfinancial incentives, both extrinsic -i.e, training, job security and promotion- and intrinsic -i.e., involvement, self-fulfillment, autonomy, recognition of one's contribution and good work schedule-. These features, typical of the nonprofit sector, enrich the evaluation of the interdependence among the main factors of the organizational design.

Another contribution of our study is the methodology applied to carry out the empirical analysis. We examine the relation between the delegation of authority and the extent of incentive compensation using a simultaneous equation model. Together with the sample selection procedures, this model allows us to address some of the endogeneity problems, although we are aware that some problems are likely to remain, and our findings should be interpreted accordingly.

\section{Agency Theory in Nonprofit Organizations}

[7], [8] and [9] confirm the relations outlined between delegation of decision rights and incentive compensation under the agency approach to a firm's framework. Although the application of agency theory is widespread throughout the literature on the for-profit sector, little consensus seems to exist on the applicability of classical agency theory in the case of non-profit organizations [10], [11] and it is not yet commonly used to describe labour relations in non-profit organizations. Still, as [12] notes, there is no basis to think that non-profit organizations are spared from "moral hazard, opportunism, adverse selection and other problems of asymmetric information". Agency theory framework can be applied to nonprofit organizations if some peculiarities of this sector are taken into consideration as shown several empirical and theoretical studies [11], [13], [14], [15], [16], [17]. More research is therefore needed.

Principal-agent relations in non-profit organizations are even more problematic than in for-profit firms because of the lack of ownership incentives, complex and vague mission [15], lack of a single overriding objective [11] and even the absence of consensus on the identity of one single principal [14].

The concept of ownership is relatively straightforward in the corporate world, but the term is rather ambiguous in the non-profit sector. Non-profit organizations, as opposed to for-profit organizations, do not have shareholders per se since rights over the surpluses generated by a non-profit organization are not alienable [18]. Thus, in a not-for-profit organization, there are no residual claims to be paid out and no owners expecting to earn a profit [13].

Following [19], [20], the principal, or owner, of the nonprofit organization is the donor. These authors argue that not only does donor capital replace equity capital in non-profit organizations, but donors, especially large donors, also displace shareholders in monitoring management activities. Since the return to donor capital is nonmonetary, donors do not have a direct and immediate incentive to attend to dysfunctional organizational behaviour [18]. Hence, the proper incentives for monitoring organizational activities and reduce wastage in non-profit organization are likely to be absent.

In addition, nonprofits lack clearly defined ownership rights, thus eliminating the main reason for contributors to supervise internal agents' performance. However, this lack of definition does not mean an absolute disregard for the right assignment of their contributions, to the extent that the absence of residual rights in nonprofit organizations does not mean that donors assume no residual risk.

Contributors who assume the residual risk of the assignment of their resources are in a position to watch the activity of the organization. In so doing, they can demand an active participation in the organization either to supervise the destination of their contributions or to determine the use of their funds (especially in the case of institutional donors) including how their funds are distributed in terms of the amount, time, and organization [16]. Although not financial, contributors anticipate a return from their investments and will invest elsewhere if their expectations are not met [13]. In this regard, the nonprofit sector's decision system is similar to the for-profit sector's decision system, with a separation between decision-making (i.e., initiation and implementation) and the assumption of the risks that leads to the control of decisions (ratification and supervision) [19], [20]. Even so, the application of the agency theory to nonprofit organizations must be done cautiously, because incentive compensation systems function differently within the nonprofit sector, compared to the for-profit sector [21], [22], as we address in the following discussion. In fact, the nondistribution constraint does not allow non-profit organizations to disburse profits to their constituencies, but rather these benefits must be used within the organizations themselves.

\section{Hypotheses Development}

Agency theory argues that principals should design incentive systems to induce their agents to undertake the desired actions [23]. In the case of nonprofit organizations, as previously discussed, incentive compensation schemes are created far differently from for-profit firms, which focus primarily on financial extrinsic rewards such as individual and financial advancement. Conversely, non-profit incentive programs commonly seek a mutual trust that reinforces the identification of the individual with the organization's identity. In this line, non-profits give greater importance to non-financial extrinsic incentives and intrinsic incentives, that is, "soft incentives" that do not involve financial gain but rather impact the agent's behaviour through the fulfilment of the organization's goals and mission [22]. However, within the confines set by the non-distribution constraint, several 
financial extrinsic incentives can be applied [15].

Nonetheless, the contributors of resources (the only principal taken into consideration) to non-profit organizations transfer decision rights to knowledge sources (in a process similar to for-profit firms), provided that transfer costsderived from the design of the incentive compensation program - do not exceed the benefits that arise from granting these rights [5], [24]. We thus expect that as delegation increases, managers will increasingly use incentive compensation, which is defined for our purposes as a mix of both intrinsic and extrinsic rewards. Thus, we state the first hypothesis:

$\mathrm{H}_{1}$ : A high level of delegation within non-profit organizations is positively related to a high level use of incentive compensation.

Agency theory generally assumes the agent is not very keen on taking risks: that is, the agent is assumed to be riskaverse (he/she will prefer a fixed compensation instead of incentive compensation that yields the same average amount), so the agent can only be persuaded to opt for incentive compensation when the average compensation level is significantly higher than the one under the fixedcompensation option [11]. This compensation, called the risk premium, is the incentive related-cost of delegation. In nonprofit organizations, as well as in firms, efficient employment contracts balance the gains from providing incentives and rewards to employees with the costs of imposing risk on the agents [6]. Because incentive compensation imposes risk on risk-averse agents, there is a cost of delegation, which management trades off with the benefits of delegation [7]. Therefore, a negative relation is expected between high incentive compensation levels for employees at the delegated level and greater delegation, leading us to the second hypothesis:

$\mathrm{H}_{2}$ : A high level of incentive compensation in non-profit organizations is negatively related to a high level of delegation.

We draw on [1], [5], [6] to argue that granting decision rights and applying incentive compensation are interrelated choices. The following two equations summarize our conceptual model:

$$
\begin{aligned}
& \text { Incentive compensation }=\mathrm{f}(\text { delegation of authority, test variables, control variables }) \\
& \text { Delegation of authority }=\mathrm{f} \text { (incentive compensation, test variables, control variables) }
\end{aligned}
$$

We use equations (1) and (2) as the basic model to assess the interdependence between delegation and incentive compensation. The choice of performance measurement is another important aspect of organizational design [1], [5] as it directly influences both delegation and incentive compensation. Although we recognize performance measurement as a complementary choice, because we base our study on NGDOs, we do not include it in our model, following [7]. NGDOs use a set of performance measures based on the logical framework approach-a management tool widely accepted in the international development cooperation field mainly used in the design, monitoring, and evaluation of development projects. Most public institutional donors and many large private contributors ask that projects that they fund be designed according to the logical framework approach because it imposes rigor in assessing goals, achievements, and the assumptions behind what interventions and activities will be required. Nevertheless, applying this approach does not mean that donors impose a strict set of measures but rather that they suggest the basic points to be controlled so that the organizations can design their own specific performance measurements.

\subsection{Determinants of the Use of Delegation of Decision Rights}

Performance measurement. The delegation of authority involves an ex ante assignment of responsibilities based on the results. The availability of informative performance measurements better enables managers to judge the actions of their subordinates [25] and, in turn, to delegate more authority to these lower level employees [26]. Consequently, performance measurement reduces employees' potential to develop opportunistic behaviours based on their specific knowledge. According to this approach, delegation is determined by managerial capacity to observe the degree of mission achievement (i.e., in the case of NGDO, the accomplishment of deadlines established by the logical framework). Thus, we expect a positive relation between higher levels of performance measurement and higher levels of delegation of authority.

Knowledge of the organizational culture. All organizations develop their activities using a framework that their members internalize. These general rules, also known as organizational culture, which guide the behaviour of individuals in a certain direction, can also fulfil a role in the coordination of activities. The culture acts as a motivational and coordination mechanism in organization through the homogenization of behaviour, a feature that makes possible the creation of predictability, order, and consistency [1]. A complex organizational culture requires more time for employees to assimilate so that they can understand the operating mode of the organization. Thus, we expect a negative relation between a more embedded and complex organizational culture that requires more time to be understood by employees and a higher delegation of decision rights.

Organization size. Organizational size strongly influences the extent of delegation choice. A large size involves a greater division of work, allowing the organization to benefit from the advantages of higher specialization and the progressive creation of organizational units, thus reinforcing the development of technical and professional tasks [27] and bringing about a greater delegation of authority [28], [29]. Therefore, we expect a 
positive relation between the size of the organization and the delegation of decision rights.

\subsection{Determinants of the Use of Incentive Compensation}

Performance measurement. To design a system of incentives so that the agents may foster the fulfillment of the organization's aims, a measurement system is necessary to outline the results obtained. The information principle argues that performance measurements can be used if that they provide new information [6], [30] to principals that allow them to offer incentives to the agents to guarantee the achievement of their goals. Therefore, we expect a positive relation between the use of performance measurements and the use of incentive compensation.

Knowledge of the organizational culture. One of the main effects of the organizational culture on organization performance is that it increases the consistency of people's behaviour. That is, organizational culture indicates to employees the behaviour they should adopt and the behaviour they should avoid [31], thus strengthening the system of rules and the configuration of power. Logically, complex organizations require more time for individuals to acclimate and adapt to these behavioural rules and, additionally, make more difficult to attribute performance to specific individuals. Reward systems are therefore implemented more slowly as an extended tenure with these organizations is required to adopt the organizational culture fully. We, thus, expect a negative association between a complex organizational culture that requires more time to be understood by employees and the use of incentive compensation.

Organization size. Another effect observed in organizations when they increase their size is that the channel through which information flows get longer, increasing the possibilities to introduce noises and distortions to the benefit of individuals and to the detriment of the organization. These distortions generate costs for the organization because decisions adopted can be inefficient and because part of the production time is used by individuals in activities of pressure and influence [32]. Therefore, as organization size increases, the frequency of incentive compensation also increases to reduce the influence costs and to align the interests and objectives of an increasing number of people with diverse utility functions. Thus, we expect a positive association between the size of the organization and the use of incentive compensation.

\section{Methods}

\subsection{Sample}

Similar to [7], our sample consists of organizations from a single sector (i.e., the international development cooperation sector); we thus avoid the usual analysis of the different settings consistent with a large number of heterogeneous organizations.

NGDOs focus their activity on the performance of development cooperation projects and humanitarian aid operations in developing countries, channelling funds obtained in the well-developed countries. Although these organizations must carry out numerous complementary activities (e.g., fundraising, awareness campaigns, attracting volunteers) to fulfil their mission, their projects department defines the reason for their existence. Therefore, operating on the assumption that the success or failure of this department is critical to these organizations, we analyse the interdependence of delegation and incentive compensation at the NGDO's project department.

In Spain, NGDOs are among the most dynamic in the nonprofit sector [16], [33], managing resources that exceeded $€ 1,000$ million in $2005, € 1,200$ million in $2006, € 1,315$ million in $2007, € 1,400$ million in $2008, € 1,480$ million in 2009 and $€ 1,525$ million in 2010 (the latest year for which information is available). These results show the consolidation that Spanish NGDOs have experienced as key players in the international development cooperation field in recent years. The increase in funds managed by the NGDOs is a result of a substantial portion of public funds-from the national government, regional governments, and the European Union - channelled to international development cooperation through the NGDOs, and higher awareness among the people of the northern hemisphere well-developed countries, which has resulted in an increase in private donations.

Our final sample consists of 37 NGDOs registered both in the Spanish Federation of Nongovernmental Development Organizations $^{1}$ and in the Spanish Agency for International Development Cooperation. NGDOs, due to their legal form (i.e., foundations and public associations) are under a strict regulatory control and are required to submit financial records annually to their respective national registry (i.e., the one for foundations or public associations). The organizations in our sample represent approximately $80 \%$ of the total employment within the international development cooperation sector and receive more than $65 \%$ of the total donations granted by the Spanish Agency for International Development Cooperation to Spanish NGDOs. Thus, we confirm that our sample is comprised of a set of organizations that are a good reflection of the Spanish development cooperation sector.

\subsection{Variables}

Several measures, such as the level of delegation of decision rights and the incentive compensation, are based on prior empirical research and, when possible, measured with multiple variables adapted to nonprofits. Where multiple variables are used to measure construct, we use the factor score. We apply principal component analysis as extraction

\footnotetext{
1 This federation (http://www.congde.org) includes the most active Spanish NGDOs -89 organizations in 2010 (the latest year for which information is available)-. Its activities are intended to enhance NGDOs' credibility, transparency, and involvement in international cooperation; to coordinate the NGDOs' activities; and to raise public awareness of the international cooperation. The federation has published directories from 1995 with relevant information concerning internal structure of the federated NGDOs.
} 
method and retain factors with an eigenvalue greater than unity. We use a questionnaire designed following [9] and adapted to non-profits. Data were collected through personal in-depth interviews with those responsible for the projects department in each of the 37 NGDOs in our sample.

\subsubsection{Choice Variables}

Delegation of decision rights (DEL). We measure the extent of delegation adapting to NGDO a version of the [8], [34] instrument. We capture the authority of the project department employees on a range of six key decisions related to the logical framework approach (i.e., identification, formulation, selection, resource allocation, evaluation, and fund-raising) along a Likert-type scale of 1 (superior has all the influence) to 5 (employee has all the influence). Chi-squared tests and the Cronbach alpha statistic (0.73) support the use of the six-items measure as a unidimensional construct.

Incentive compensation (INC). Although we are aware that intrinsic incentives play a very important role in this type of organizations, as supported by a large body of theoretical research, these rewards are almost impossible for the organization to control. Therefore, we only consider extrinsic rewards provided to hired staff. We develop a construct that includes five items based on prior empirical studies, such as labour stability [35], [36], [37], training [36], [38], [39], promotion [35], [36], [39], travel reimbursements, expense account and allowances [36], [37], [40] and percentage change in base salary [21], [36], [37], [39], measured along a Likert-type scale of 1 (incentive is hardly used) to 5 (incentive is used to a very large extent). We do not consider performance-based cash compensation because this incentive type is not used in Spanish NGDOs. Chi-squared tests and the Cronbach alpha statistic (0.75) support the use of the five-items measure as a unidimensional construct.

Table 1. Descriptive Statistics for Endogenous Variables.

\begin{tabular}{llll}
\hline & Mean & Median & Std. Dev. \\
\hline DEL1 & 3.97 & 4.00 & 1.082 \\
DEL2 & 3.65 & 4.00 & 1.252 \\
DEL3 & 3.19 & 3.00 & 1.175 \\
DEL4 & 3.28 & 3.00 & 1.233 \\
DEL5 & 3.47 & 4.00 & 1.362 \\
DEL6 & 2.89 & 3.00 & 1.430 \\
INC1 & 2.44 & 2.00 & 1.362 \\
INC2 & 3.19 & 3.00 & 1.489 \\
INC3 & 2.00 & 1.00 & 1.309 \\
INC4 & 2.44 & 2.00 & 1.557 \\
INC5 & 3.17 & 4.00 & 1.682 \\
\hline
\end{tabular}

DEL1: Project identification; DEL2: Project formulation; DEL3: Project selection; DEL4: Resource allocation and project performance; DEL5: Project evaluation; DEL6: Search for sources of finance; INC1: Labor stability; INC2: Promotion; INC3; Training: INC4: Travel reinbursements, expense account and allowances; INC5: Percent change in base salary

\subsubsection{Test Variables}

Performance measurement (PERF). We propose a six-item scale related to the logical framework approach as well as the mission and objectives of the NGDOs -involvement of the beneficiaries, relationships with your counterparts, project quality, project identification, project formulation and project selection-. The respondents rated the importance of each item in how they measure their employees' performance using a fully anchored five-point Likert-type scale from 1 (I never use it) to 5 (I always use it). Chi-squared tests and the Cronbach alpha statistic (0.74) support the use of the sixitems measure as a unidimensional construct.

Table 2. Matrix of the factor analysis components: Composition of the component matrix.

\begin{tabular}{llll}
\hline & Coefficient & Eigenvalue & Variance (\%) \\
\hline $\begin{array}{l}\text { Delegation of decision } \\
\text { rights (DEL) }\end{array}$ & & 3.18 & 45.47 \\
DEL1 & 0.739 & & \\
DEL2 & 0.888 & & \\
DEL3 & 0.614 & & \\
DEL4 & 0.721 & & \\
DEL5 & 0.694 & & \\
DEL6 & 0.679 & & \\
Incentive systems (INC) & & 2.19 & \\
INC1 & 0.691 & & \\
INC2 & 0.572 & & \\
INC3 & 0.687 & & \\
INC4 & 0.551 & & \\
INC5 & 0.783 & & \\
Performance & & \\
measurement (PERF) & & \\
PERF1 & 0.526 & & \\
PERF2 & 0.798 & \\
PERF3 & 0.477 & \\
PERF4 & 0.869 & \\
PERF5 & 0.882 & \\
PERF6 & 0.767 & & \\
\hline
\end{tabular}

Notes: Principal component analysis as extraction method. Each factor presents the variables with factor loadings greater than 0.45 .

Knowledge of the organizational culture (KCRIT). Drawing on previous empirical research [41], [42], we measure this variable by means of a proxy that takes into account the time a new employee requires to develop critical knowledge of the organizational culture of the NGDO. The project department coordinators response is rated on a fully anchored Likert scale from 1 (less than one year) to 5 (more than five years).

Size (PROJ). We define size as the number of present and prospective projects the organization has under funding or presented for funding, respectively, at the present time (PROJ). In other words, we use project number as a proxy for size in the same way that annual sales are used to capture the firm size of for-profit firms $[24]^{2}$.

\subsubsection{Control Variables for Equation 1 (Incentive Compensation)}

Managerial tenure (TEN). The tenure of a non-profit's founder and the continuity of the general manager are signals of the persistence of the original goals for which the NGDO was founded. They will seek to hire individuals who share

2 The average total expense per project is quite similar in the sample organizations. All of the organizations show values which do not vary more or less than $10 \%$ of that average value. Similar results were obtained when we estimated the average total expense per project for the previous two years. 
their vision so that strict control will not be necessary to direct employees toward achieving the founder's objectives [43]. However, the intrinsic motivation of the employees is costly and fragile [44] and therefore must be strengthened and complemented with extrinsic motivation. Thus, we expect a positive relation between the continuity of the founder/manager of the organization and the use of incentive compensation. This variable is measured as the number of years the founder of the organization/general manager, if this position is not performed by the same person, have been running the organization, following previous studies [25].

Span of control (SPAN). Span of control measures on the intensity and frequency with which the manager interact with his or her subordinates. It is negatively related to complexity - that is, the more different the activities are under a manager's supervision, the fewer will be the number of subordinates that can be controlled [45]. An appropriate span of control is very important for the organization because a span that is too wide can involve a loss of control of subordinates, giving rise to conflicts of interest as a result of the search for private objectives over organizational objective. Conversely, span that is too narrow implies an underuse of managers' time, which is limited and expensive. Thus, we concede that the span of control influences the organization's incentive system and expect a positive relation between a higher span of control and a greater use of incentive compensation. We measure this variable by the number of employees supervised by the project department coordinator, a widely accepted measure in the literature [4], [46].

\subsubsection{Control Variables for Equation 2 (Delegation of Authority)}

Formalization (FORM). The formalization of organizational activities implies the development of routines or rules that restrict the action of each individual or organizational unit to behaviours that are consistent with the actions of other individuals or units with which they have interdependencies [47], [48]. Thus, formalization within an organization develops behavioural patterns in which staff makes decisions with no discretionary margin. Therefore, we expect a negative relation between formalization and delegation of decision rights. Following the studies of [34], [46], we measure formalization of procedures as the extent to which the organization has manuals of practices and rules to perform the tasks. The respondents answer on a fully anchored Likert scale from 1 (not at all) to 5 (yes, for everything).

Individual specific knowledge (EDUC). The retention of well-trained employees implies a change in the balance of power in the employer-employee relationship, mainly among highly qualified employees who carry out tasks with a great amount of knowledge or with specific abilities. Organizations benefit from the knowledge of highly qualified employees when they use these employees' tacit knowledge for both strategic and tactical decision making [49]. Therefore, we expect a positive relation between the level of knowledge of the employee and delegation of decision rights because the knowledge potential of the employees allows them to make decisions over a wide range of activities. We capture the specific knowledge level as the employees' education level, a well-known variable in the literature [25], [46]. We ask respondents to indicate on a Likert scale from 1 (no studies) to 5 (postgraduate) what education level their staff needs to fulfil their jobs.

Table 3. Descriptive Statistics.

\begin{tabular}{llll}
\hline & Mean & Median & Std. Dev. \\
\hline LEVEL & 3.11 & 3.00 & 0.994 \\
SPAN & 16.35 & 11.00 & 22.983 \\
EDUCATION & 4.03 & 4.00 & 0.866 \\
TENURE & 8.86 & 5.00 & 9.516 \\
AGE & 20.03 & 15.00 & 22.254 \\
INCOME & 8785863.43 & 4832286.00 & 10953117.616 \\
PROJ & 60.12 & 25.00 & 92.342 \\
\hline
\end{tabular}

LEVEL: Number of hierarchical levels; SPAN: Number of employees supervised by the project department coordinator; EDUCATION: education level employees of the project department need to fulfil their jobs; TENURE: number of years the founder of the organization and the general manager, if this position is not performed by the same person, have been running the organization; AGE: Age of the organization; INCOME: Total monetary income of the organization equal to private donations plus public subsidies; PROJ: Number of present and prospective projects;

\subsection{Model and Econometric Issues}

Our analysis is based on a model of partial equilibrium in which the remainder of organizational design choices - with the exception of the delegation of decision rights and incentive compensation-are considered as exogenous variables. To test our hypotheses, we use a simultaneous equations model because the endogenous variables DEL and INC are jointly determined in equilibrium. Ordinary least squares estimation may be inappropriate [50] because we cannot account for the influence that each variable has on the other. Our system of equations is described as follows:

$$
\begin{gathered}
\mathrm{INC}=\alpha_{0}+\alpha_{1} \mathrm{DEL}+\alpha_{2} \text { PERF }+\alpha_{3} \text { KCRIT }+\alpha_{4} \text { PROJ }+\alpha_{5} \text { TE } \\
\mathrm{N}+\alpha_{6} \text { SPAN }+\varepsilon_{1 \mathrm{tt} .} \\
\mathrm{DEL}=\beta_{0}+\beta_{1} \mathrm{INC}+\beta_{2} \text { PERF }+\beta_{3} \text { KCRIT }+\beta_{4} \text { PROJ }+\beta_{5} \text { FO } \\
\mathrm{RM}+\beta_{6} \text { EDUC }+\varepsilon_{2 \mathrm{t}} .
\end{gathered}
$$

Before the estimation of the simultaneous equation model, we verify the endogeneity of the variables under analysis through the Hausman test (indicates significant endogeneity at the $0.01 \%$ level). Additionally, in all specified equations, more exogenous are excluded than endogenous variables included so that the order condition is fulfilled. We also verify the range condition so that we can perform a joint measurement of the system through the different methods applicable to simultaneous equations. Specifically, we perform the estimate through the two-stage least squares method, which uses a limited information approach that 
estimates each equation separately. This method accounts for all the variables in the model, including those that are both included and excluded in the equation. It does not, however, account for the particular specification of the other equations, although the requirements of this technique are adequate for our small sample size.

\section{Results}

The results of the two-stage least squares estimation of the model are shown in table 4 . The first column of Table 4 presents the results of equation (3). Contrary to our expectation, when delegation increases, we find that incentive compensation is used less to align individual objectives with organizational objectives $\left(\mathrm{H}_{1}\right)$. This result can be explained by the unique place of intrinsic incentives within nonprofit organizations; namely, the increase of the responsibilities involved with delegation can become a powerful enough motivation to match individual and organizational aims [21], [22].

We find that a greater use of performance measurements increases the information available about agents related to the achievement of objectives addressed to guide their behaviour, rewarding those who contribute to a great extent and penalizing those whose private interests take precedence over the organizational mission.

Our findings also indicate that the size of the organization (PROJ), and the tenure of the founder/ general manager (TEN) are significant and positively associated with the extent of incentive compensation, whereas a more complex set of organization's culture and values (KCRIT) has a negative and significant effect on the use of incentive compensation, as predicted.

The negative relation between the span of control (SPAN) and the use of incentive compensation is inconsistent with principal-agent theory because a wide span of control involves less strict control of subordinates, offering the chance to opportunistic behaviours. However, as the span of control widens, the number of individuals under the direct supervision of a manager increases. A wider span, thus, suggests that these employees operate with a greater degree of autonomy and value another type of incentive, namely, those with a more intrinsic component. Thus, the need for extrinsic incentives to align the interest of these subordinates with the organization's objectives is lower.

The second column of Table 4 presents the results of equation (4). Results provide strong evidence that a greater use of incentive compensation has a negative effect on delegation levels $\left(\mathrm{H}_{2}\right)$. Incentives are the cost involved in delegation; therefore, to determine whether to delegate, the cost of knowledge transfer to the decision maker must be weighed against the control costs derived from the incentives provided to the agent to achieve the alignment of interests and to avoid the inconsistency of objectives. As control costs increase, delegation decreases because the benefits obtained by decisions adopted with better knowledge and more relevant information of the problem will be offset.

A greater application of performance measurements (PERF) improves the control of the agents as it provides broader information on the activities they perform and on the results they obtain. Thus, stronger performance measures reduce the potential that agents may develop opportunistic behaviours by using their knowledge to achieve their own aims to the detriment of the organization's objectives.

Results also show that formalization (FORM) has a positive effect on delegation, which is unexpected and contrary to our expectations. We posit that managers think that they delegate when they greatly formalize their activities, without realizing they are doing the opposite. That is, they reduce the discretionary capacity of the agents and thereby constrain any potential problems of opportunism.

A more complex set of organizational culture and values that requires more time to be understood by employees (KCRIT) relates negative and significantly with the delegation of authority; that is, the delegation of decision rights is lower when individuals take longer to understand the operating mode of an organization and achieve their coworkers' level of experience. In other words, if they do not know the idiosyncrasies of the organization, they are not ready to assume greater responsibilities. The specific knowledge of the individual (EDUC) and the size of the organization (PROJ) show a positive influence on the extent of delegation of decision rights, as expected, although the first relation is not significant.

Table 4. Equations and results of the two-stages least squares estimation.

\begin{tabular}{|c|c|c|c|c|}
\hline \multirow[b]{2}{*}{ Regressors } & \multicolumn{2}{|c|}{$\begin{array}{l}\text { Equation (3): INC }=\alpha_{0}+\alpha_{1} \text { DEL }+\alpha_{2} \text { PERF }+\alpha_{3} \text { KCRIT }+ \\
\alpha_{4} \text { PROJ }+\alpha_{5} \text { TEN }+\alpha_{6} \text { SPAN }+\varepsilon_{1 \mathrm{t}}\end{array}$} & \multicolumn{2}{|c|}{$\begin{array}{l}\text { Equation (4): DEL }=\beta_{0}+\beta_{1} \text { INC }+\beta_{2} \text { PERF }+\beta_{3} \text { KCRIT }+ \\
\beta_{4} \text { PROJ }+\beta_{5} \text { FORM }+\beta_{6} \text { EDUC }+\varepsilon_{2 t}\end{array}$} \\
\hline & Predicted sign & Coefficient ( $t$-statistic) & Predicted sign & Coefficient ( $t$-statistic) \\
\hline INTERCEPT & & $\begin{array}{l}1.137 \\
(1.802)\end{array}$ & & $\begin{array}{l}1.500 \\
(1.608)\end{array}$ \\
\hline DEL & + & $\begin{array}{l}-0.490^{* *} \\
(-2.342)\end{array}$ & & \\
\hline INC & & & - & $\begin{array}{l}-0.401^{* *} \\
(-2.277)\end{array}$ \\
\hline PERF & + & $\begin{array}{l}0.502^{* * *} \\
(2.852)\end{array}$ & + & $\begin{array}{l}0.335^{* *} \\
(2.047)\end{array}$ \\
\hline KCRIT & - & $\begin{array}{l}-0.716^{* * *} \\
(-2.814)\end{array}$ & - & $\begin{array}{l}-1.010^{* * *} \\
(-4.709)\end{array}$ \\
\hline PROJ & + & $\begin{array}{l}0.730^{* * *} \\
(3.803)\end{array}$ & + & $\begin{array}{l}0.555^{* * *} \\
(3.636)\end{array}$ \\
\hline TEN & + & $0.038^{* *}$ & & \\
\hline
\end{tabular}




\begin{tabular}{|c|c|c|c|c|}
\hline \multirow[b]{2}{*}{ Regressors } & \multicolumn{2}{|c|}{$\begin{array}{l}\text { Equation (3): INC }=\alpha_{0}+\alpha_{1} \text { DEL }+\alpha_{2} \text { PERF }+\alpha_{3} \text { KCRIT }+ \\
\alpha_{4} \text { PROJ }+\alpha_{5} \text { TEN }+\alpha_{6} \text { SPAN }+\varepsilon_{1 \mathrm{t}}\end{array}$} & \multicolumn{2}{|c|}{$\begin{array}{l}\text { Equation (4): DEL }=\beta_{0}+\beta_{1} \text { INC }+\beta_{2} \text { PERF }+\beta_{3} \text { KCRIT }+ \\
\beta_{4} \text { PROJ }+\beta_{5} \text { FORM }+\beta_{6} \text { EDUC }+\varepsilon_{2 t}\end{array}$} \\
\hline & Predicted sign & Coefficient ( $t$-statistic) & Predicted sign & Coefficient ( $t$-statistic) \\
\hline SPAN & + & $\begin{array}{l}(2.290) \\
-0.945^{* *} \\
(-2.252)\end{array}$ & & \\
\hline FORM & & & - & $\begin{array}{l}0.353^{* *} \\
(2.438)\end{array}$ \\
\hline EDUC & & & + & $\begin{array}{l}0.263 \\
(1.355)\end{array}$ \\
\hline$N$ & & 37 & $N$ & 37 \\
\hline$R^{2}$ & & 0.460 & $R^{2}$ & 0.540 \\
\hline Adj. $R^{2}$ & & 0.329 & Adj. $R^{2}$ & 0.448 \\
\hline
\end{tabular}

$* \mathrm{p}<0.10, * * \mathrm{p}<0.05, * * \mathrm{p}<0.01$ (two-tailed)

\section{Conclusions}

This study develops a better understanding of the determinants of organizational design choices and the interrelation between those choices. Specifically, we analyse two key organizational design choices facing managers of Spanish NGDOs: delegation of authority and the provision of incentive compensation to deter discretionary misuse. Our results are generally consistent with our expectations based on agency theory. However, some discussion and considerations are necessary.

First, incentive systems that can be used in NGDOs are wide enough, and both extrinsic and intrinsic are involved in their design. Thus, our result that greater delegation is not associated with greater use of incentive compensation is somewhat surprising, as we expect it would be positively associated following the agency theory. This result is of interest to NGDOs managers because it shows the importance of intrinsic incentives and the need to develop actions to maintain and enhance this type of motivation that largely differentiates non-profits employees from for-profit employees.

Second, incentive compensation as a major cost of delegation is also significant in NGDOs. Our results show that when incentive cost is high, the extent of authority delegated to the agent tends to decline. Although delegation may be justified by higher quality decision making, managers of NGDOs should not lose sight that they have very limited resources allowed for very specific purposes.

Third, the extent of delegation is associated with the use of performance measurements that are a perfect reflection of development cooperation activities, which is logical, provided NGDOs can operate in unstable and uncertain environments, where the results of the agents' activity are not perceptible. Taking into account that development cooperation projects work toward multiple objectives -some of which are very difficult to measure- and are subject to multiple contingencies due to existing deprivations in operating areas, much more room for improvement still exists in the design of accurate performance measures, even though substantial progress has been made.

Fourth, greater reliance on the use of incentive compensation promotes a greater use of performance measurements. NGDOs managers must emphasize this issue because one of donors' main concerns related to the use of incentives is that resources are used to increase staff wages instead of performing projects for which they were granted. Showing that these incentives have been associated with higher performance control will help to eliminate this mistrust and help improve the efficiency of the organization.

Fifth, the control variables that previous studies have considered relevant determinants of the delegation and incentive compensation choices show significant explanatory power. We emphasize the importance this type of organization grants to the knowledge of its internal culture. This aspect is an integrative element of the organization, which requires that staff, despite being highly qualified, spend important periods of time assimilating to the organization's goals and values.

Finally, size stands out as a major element for the delegation and incentive compensation choices. These organizations are often derived from small groups of individuals that devote their time and efforts altruistically. As they extend their geographical and operating environment, the number of employees and the amount of financial resources increase as does their need for a more professional organizational design. Consequently, they must adapt their organizational design to meet these new challenges of an uncertain and highly dynamic environment.

\section{Discussion and Limitations}

As motivation is substantially different between non-profit organizations and firms' employees, when transferring certain extrinsic incentives that have proved valid in the forprofit sector, NGDOs managers would be well served to know how and under what conditions these extrinsic incentives should and should not be applied in the non-profit sector. Additionally, the application of incentives must be fully justified in terms of the provided advantage and cannot violate the non-distribution constraint.

The generally held social perception of a lack of performance measurement systems in non-profits is unfounded. The organizations under analysis, although implicitly, measure employees' performance. In addition, performance measurements are used frequently as professionalism and qualification markers, and 
consequently, the delegation levels of the employees increase. In this sense, NGDOs managers should make a major communication effort to send a clear message to society: performance is a key issue in the non-profit sector to improve its efficiency.

Although delegation is the current trend, it is not always the optimal option. This way, we cannot establish beforehand an optimal delegation-incentive compensation choice for each organization as a number of factors influence that choice. A non-profit's choice will depend on the required knowledge to make the decision, as well as on the control and incentive systems that are implemented for each organizational situation.

The findings of this study are subject to three important caveats. First, we use a partial equilibrium analysis because no empirical study can model simultaneously all the organizational design choices. Second, a potential for measurement error exists because the data obtained from the questionnaires are based on the perceptions of respondents, which can cause biases. However, the use of multi-item scales also mitigates some of the measurement error concerns. Third, the isolation process of exogenous variables to identify the simultaneous equations is difficult and, consequently, other determinants of organization design choices and other control variables may exist that influence delegation and incentive compensation choices.

Despite these limitations, this study makes an important contribution to empirical literature on organizational design choices by analysing simultaneously the interrelated nature of delegation and incentive compensation. Moreover, it applies to the currently relevant field of NGDOs, which is less studied; to the best of our knowledge, no evidence exists on this interrelation. This research provides with one of the first empirical studies of the joint nature of delegation and incentive compensation in the non-profit sector.

\section{References}

[1] Brickley, J. A., Smith, C. W. \& Zimmerman, J. L. (2004). Organizational architecture: A managerial economics approach, 3rd ed., Boston, MA: Irwin/McGraw-Hill.

[2] Jensen, M. C. \& Meckling, W. H. (1976). Theory of the firm: Managerial behavior, agency costs, and ownership structure. Journal of Financial Economics, 3(4), 305-360.

[3] Mirvis, P. H. \& Hackett, E. J. (1983). Work and work force characteristics in the nonprofit sector. Monthly Labor Review, 106(4), 3-12.

[4] Lambert, R. A., Larcker, D. F. \& Weigelt, K. (1993). The structure of organizational incentives. Administrative Science Quarterly, 38(3), 438-461.

[5] Jensen, M. C. \& Meckling, W. H. (1992). Specific and general knowledge and organizational structure. In L. Werin \& H. Wijkander (Eds), Contract Economics (pp. 251-274), Oxford: Blackwell.

[6] Milgrom, P. \& Roberts, J. (1992). Economics, Organization, and Management. Englewood Cliffs, CO: Prentice-Hall.
[7] Nagar, V. (2002). Delegation and incentive compensation. The Accounting Review, 77(2), 379-395.

[8] O'Connor, N. G., Deng, J. \& Luo, Y. (2006). Political constraints, organization design and performance measurement in China's state-owned enterprises. Accounting, Organizations and Society, 31(2), 157-177.

[9] Widener, S. K., Shackell, M. B. \& Demers, E. A. (2008). The juxtaposition of social surveillance controls with traditional organizational design components. Contemporary Accounting Research, 25(2), 605-638.

[10] Steinberg, R. (1990). Profits and incentive compensation in nonprofit firms. Nonprofit Management and Leadership, 1(2), $137-152$.

[11] Caers, R., Du Bois, C., Jegers, M., De Gieter, S., Schepers, C. $\&$ Pepermans, R. (2006). Principal-agent relationship on the stewarship-agency axis. Nonprofit Management and Leadership, 17(1), 25-47.

[12] Slivinski, A. (2002). Team incentives and organizational form. Journal of Public Economic Theory, 4(2), 185-206.

[13] Olson, D. A. (2000). Agency theory in the not-for-profit sector: Its role at independence college. Nonprofit and Voluntary Sector Quarterly, 29(2), 280-296.

[14] Miller, J. L. (2002). The board as a monitor of organizational activity: The applicability of agency theory to nonprofit boards. Nonprofit Management and Leadership, 12(4), 429450 .

[15] Du Bois, C., Caers, R., Jegers, M., Schepers, C., De Gieter, S. \& Pepermans, R. (2009). Agency conflicts between board and manager. A discrete choice experiment in Flemish nonprofit schools. Nonprofit Management and Leadership, 20(2), 165183.

[16] Andrés, P., Martin, N. \& Romero, E. (2006). The governance of nonprofit organizations: Empirical evidence from nongovernmental development organizations in Spain. Nonprofit and Voluntary Sector Quarterly, 35(4), 588-604.

[17] Andrés, P., Azofra, V. \& Romero, E. (2010). Beyond the disciplinary role of governance: how boards add value to Spanish foundations. British Journal of Management, 21(4), $100-114$.

[18] Callen, J. L. \& Falk, H. (1993). Agency and efficiency in nonprofit organizations: The case of "specific health focus" charities. The Accounting Review, 68(1), 48-65.

[19] Fama, E. F. \& Jensen, M. C. (1983a). Separation of ownership and control. Journal of Law and Economics, 26(2), 301-325.

[20] Fama, E. F. \& Jensen, M. C. (1983b). Agency problems and residual claims. Journal of Law and Economics, 26(2), 327349 .

[21] Brickley, J. A. \& Van Horn, L. R. (2002). Managerial incentives in nonprofit organizations: Evidence from hospitals. Journal of Law and Economics, 45(1), 227-249.

[22] Speckbacher, G. (2003). The economics of performance in nonprofit organizations. Nonprofit Management and Leadership, 13(3), 267-281.

[23] Kreps, D. M. (1990). A Course in Microeconomic Theory. Cambridge, MA: MIT Press. 
[24] Christie, A. A., Joye, M. P. \& Watts, R. L. (2003). Decentralization of the firm. Theory and evidence. Journal of Corporate Finance, 9(2), 3-36.

[25] Abernethy, M. A., Bouwens, J. \& Van Lent, L. (2004). Determinants of control system design in divisionalized firms. The Accounting Review, 79(3), 545-570.

[26] Aghion, P. \& Tirole, J. (1997). Formal and real authority in organizations, Journal of Political Economy, 105, 1-29.

[27] Kasarda, J. D. (1974). The structural implications of social system size: A three level analysis. American Sociological Review, 39(1), 19-28.

[28] Child, J. (1973). Predicting and understanding organizational structure. Administrative Science Quarterly, 18(2), 168-185.

[29] Montanari, J. R. (1979). Strategic choice: A theoretical analysis. Journal of Management Studies, 16(2), 202-221.

[30] Holmstrom, B. (1979). Moral hazard and observability. Bell Journal of Economics, 10(1), 74-91.

[31] Trice, H. M. \& Beyer, J. M. (1993). The Cultures of Work Organization. Upper Saddle River, NJ: Prentice Hall.

[32] Milgrom, P. \& Roberts, J. (1990). Bargaining and influence costs and the organization of economic activity. In J. E. Alt \& K. A. Shepsle (Eds), Perspectives on Positive Political Economy (pp. 57-89), Cambridge: Cambridge University Press.

[33] Marcuello, C. \& Salas, V. (2001). Nonprofit organizations, monopolistic competition, and private donations: Evidence from Spain. Public Finance Review, 29(3), 183-207.

[34] Gordon, L. A. \& Narayanan, V. K. (1984). Management accounting systems, perceived environmental uncertainty and organization structure: An empirical investigation. Accounting, Organizations and Society, 9(1), 33-47.

[35] Delaney, J. T. \& Huselid, M. A. (1996). The impact of human resource management practices on perceptions of organizational performance. Academy of Management Journal, 39(4), 949-969.

[36] De Gieter, S., De Cooman, R., Pepermans, R., Caers, R., Du Bois, C. \& Jegers, M. (2006). 'Identifying nurses' rewards: A qualitative categorization study in Belgium. Human Resources for Health, 15(4), 1-8.

[37] Martín-Pérez, V., Martín-Cruz, N. \& Estrada-Vaquero, C. (2012). The influence of organizational design on knowledge transfer. Journal of Knowledge Management, 16(3), 418-434.
[38] Gomez-Mejia, L. R., Balkin, D. B. \& Cardy, R. L. (2004). Managing Human Resources. Upper Saddle River, NJ: Prentice-Hall.

[39] Martín-Pérez, V. \& Martín-Cruz, N. (2012). The mediating role of affective commitment in the rewards-knowledge transfer relation. Journal of Knowledge Management, 19(6), 1167-1185.

[40] Collins, R. A. \& Yeager, J. L. (1988). Staff evaluation and incentive practices utilized by behavioral science research organizations: A pilot study. Journal of the Society of Research Administrators, 20(1), 119-129.

[41] Gupta, A. K. \& Govindarajan, V. (1986). Resource sharing among SBUs: Strategic antecedents and administrative implications. Academy of Management Journal, 29(4), 695714 .

[42] Widener, S. K. (2004). An empirical investigation of the relation between the use of strategic human capital and the design of the management control system. Accounting, Organizations and Society, 29(3-4), 377-399.

[43] Leete, L. (2000). Wage equity and employee motivation in nonprofit and for-profit organizations. Journal of Economic and Behavior Organization, 43(4), 423-446.

[44] Frey, B. S. (1993). Motivation as a limit to pricing. Journal of Economic Psychology, 14(4), 635-664.

[45] Gibson, J. L., Ivancevich, J. M. \& Donnelly, J. H. (1994). Organizations. Behavior, structure, processes, 8th ed., Boston, MA: Irvin/McGraw-Hill.

[46] Leiter, J. (2005). Structural isomorphism in Australian nonprofit organizations. International Journal of Voluntary and Nonprofit Organizations, 16(1), 1-31.

[47] Mintzberg, H. (1992). Structure in Fives: Designing Effective Organizations. Upper Saddle River, NJ: Prentice Hall.

[48] Thompson, J. D. (1967). Organizations in Action, New York, NY: McGraw-Hill.

[49] Pfeffer, J. (1994). Competitive Advantage through People: Problems and Prospects for Change. Boston, MA: Harvard Business School Press.

[50] Greene, W. H. (1997). Econometric Analysis, 4th ed., Upper Saddle River, NJ: Prentice-Hall. 